\title{
DEM simulations of thermally activated creep in soils
}

\author{
C. -Y. KWOK* and M. D. BOLTON $\dagger$
}

Discrete element modelling (DEM) has been used to simulate creep in assemblies of spherical grains possessing an interfacial coefficient of friction that varies with sliding velocity according to rate process theory. Soil stiffness is represented by a pair of values of linear spring stiffness normal and tangential to each intergranular contact, and the limiting coefficient of contact friction is described as varying linearly with the logarithm of sliding velocity. DEM simulations of an assembly of 3451 spheres reproduce a number of significant phenomena including: creep rate as a function of the mobilisation of deviatoric stress; initially linear decay of creep strain rate with time plotted on $\log -\log$ axes and with a slope $m$ in the range -0.8 to -1 ; and ultimate creep failure in triaxial simulations at high deviatoric stress ratios. Creep-induced failure is shown to occur at a unique axial strain for a given state of initial packing, and to be linked with dilatancy. The numerical results are compared quantitatively with the test data of soils from the literature. The effects of activation energy are considered in relation to the different magnitudes of creep encountered in sands and clays.

KEYWORDS: creep; numerical modelling; time dependence
On a utilisé la modélisation aux éléments discrets pour simuler le fluage dans des ensembles de grains sphériques présentant un coefficient de friction interfaciale variant en fonction de la vitesse de glissement, conformément à la théorie du rate process. La rigidité du sol est représentée par une paire de valeurs de constante de rappel linéaire, perpendiculaire et tangentielle à chaque contact intergranulaire, et le coefficient de limitation de la friction de contact est décrit comme un coefficient variant de façon linéaire avec le logarithme de la vitesse de glissement. Des simulations par modélisation aux éléments discrets d'un ensemble de 3451 sphères reproduisent un certain nombre de phénomènes significatifs, y compris : la vitesse de glissement en fonction de la mobilisation de contraintes déviatoriques ; déclin initialement linéaire de la vitesse de fluage en fonction du temps, tracé sur des axes à double échelle logarithmique, et avec une inclinaison $m$ comprise dans la plage $-0,8$ à -1 ; et rupture par fluage limite dans des simulations triaxiales avec taux de contrainte déviatorique élevé. On démontre que les ruptures induites par fluage se produisent en présence de contraintes axiales uniques pour un certain remplissage initial, et sont en rapport avec dilatance. On effectue une comparaison quantitative des résultats numériques avec les données d'essai sur des sols extraites d'ouvrages. On examine les effets de l'énergie d'activation relativement aux différentes magnitudes de fluage relevées dans des sables et des argiles.

\section{INTRODUCTION}

Soils are rate-dependent materials. The deformation of a soil mass depends not only on the current magnitude of effective stress, but also on the rate at which the effective stress is changed or the length of time that the effective stress has been sustained. Different phenomena of time-dependent behaviour including creep, evanescent viscosity (Di Benedetto et al., 2002), stress relaxation (Lacerda \& Houston, 1973), secondary compression, ageing and strain-rate dependent shear strength (Vaid \& Campanella, 1977) are observed in the field and the laboratory. However, the underlying physical mechanisms are not clearly identified. Different mathematical models have emerged to fit the creep data of sands and clays, as well as other rate effects that are found to influence soil behaviour. In the case of clays, it is more difficult to separate the rate dependency of the soil skeleton itself from the effects of excess pore pressure dissipation or viscous drag arising from the pore fluid. Better understanding of the underlying physical processes may assist engineers to relate these various creep and rate effects, and to assess the likely influence of soil type. This paper will explore one micromechanism which may be responsible.

Manuscript received 31 January 2009; revised manuscript accepted 26 November 2009.

Discussion on this paper closes on 1 November 2010, for further details see p. ii.

* Itasca Consulting Group, Minneapolis, MN, USA (formerly

Department or Engineering, University of Cambridge, UK).

$\dagger$ Department of Engineering, University of Cambridge, UK
Soil creep has been investigated in the laboratory by researchers including Kuwano \& Jardine (2002), Hyde \& Brown (1976), Murayama et al. (1984) and Mejia et al. (1988). Creep in sands has been linked hypothetically to setup in piles driven in sands, following the observation of creep-induced dilation in triaxial tests at a high stress ratio (Bowman \& Soga, 2003). Creep may also be inferred from field tests; monitoring has shown that the delayed settlement of spread foundations on sand can be of the same order of magnitude as the immediate settlement (Burland \& Burbridge, 1985). However, the influence of the passage of time in the field is difficult to separate from the possible influence of live loads or fluctuations in the water table.

Soil creep is the progressive, irrecoverable deformation of a soil element under a state of constant effective stress. Creep rate increases significantly with deviator stress $q$, but negligibly with mean effective stress $p^{\prime}$ (except at high stress). Many researchers, such as Augustesen et al. (2004), Kuhn \& Mitchell (1993), divide the creep of soils into three stages - primary, secondary and tertiary - on a strain-time plot (Fig. 1(a)). The strain rate correspondingly decreases, then remains constant and finally increases with time (Fig. 1(b)). Tertiary creep leading to creep rupture only occurs if the stress is high enough and sufficient waiting time has been allowed.

In this paper, the rate process mechanism for creep as proposed by Kuhn (1987) is reviewed and investigated. This is implemented as a relationship between the coefficient of inter-particle friction and the logarithm of the relative velocity of contact sliding. This mechanism is incorporated into 


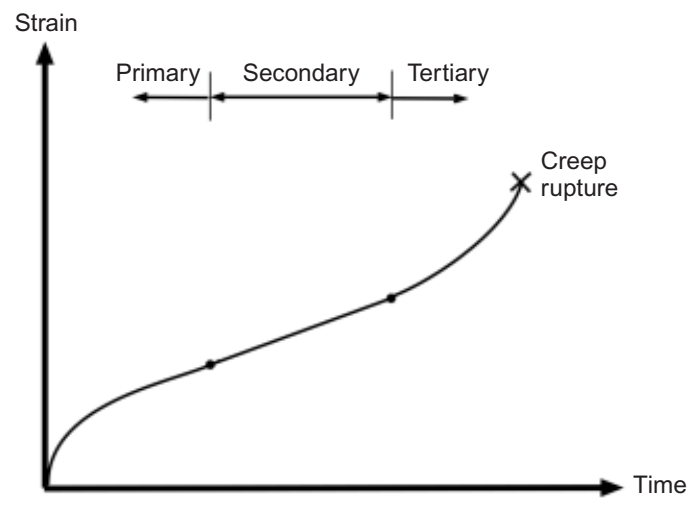

(a)

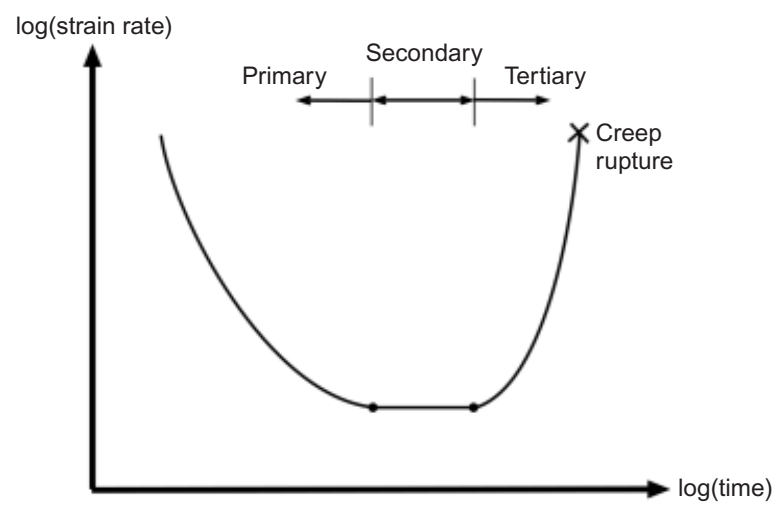

(b)

Fig. 1. Stages of creep after initial application of load or deviator stress, for creep stress that is large enough to cause failure: (a) strain plotted against time (b) $\log$ (strain rate) plotted against $\log ($ time $)$

discrete element method (DEM) simulations of the creep of a granular assembly comprising 3421 spheres. These simulations are then compared with real soil creep data published by previous research workers. The sensitivity of creep predictions to the various rate process parameters is investigated, and the credibility of values required to provide a match to real test data is discussed.

\section{MICROMECHANICS}

Several mechanisms have been proposed to account for the observed change in a soil's creep rate with time. Kuhn \& Mitchell (1993) proposed a deformation-dependent mechanism for the changing creep rate. They proposed that creep deformation is attributable to sliding between particles. The sliding velocity at each contact depends on the ratio of the tangential-to-normal components of contact force, which is the mobilised coefficient of friction. The deviator stress $\left(q=\sigma_{1}-\sigma_{3}\right)$ in a granular assembly is carried both by the tangential and normal components $\left(f^{\mathrm{t}}\right.$ and $\left.f^{\mathrm{n}}\right)$ of the contact forces. As creep deformation proceeds, particles undergo slight rearrangements that tend to reduce the tangential components and increase the normal components of the effective contact forces, reducing the velocity of inter-particle sliding with a corresponding reduction in the overall creep rate of the soil.

From this perspective, primary creep can be viewed as a natural selection process for intergranular contacts in which only the fittest, participating in a strong-force network comprising nearly-normal contacts, survive. This type of creep therefore results in more stable configurations. However, if the assembly were subjected to increased deviator stress, additional tangential sliding resistance would immedi- ately be remobilised (Bowman \& Soga, 2003) and the creep rate would suddenly increase.

Rate process theory was developed by Eyring (1936) and his co-workers to create a theory of reaction rates based on statistical mechanics applied at the atomic and molecular level. Rate process theory acknowledges that atoms, molecules and other entities are separated by energy barriers which fix their local equilibrium positions at a minimum potential energy. To surmount these barriers and permit relative movement, the acquisition of activation energy $\Delta F$ is necessary (Fig. 2). Its source is taken to be the energy of thermal vibrations of flow units $\lambda$, modified by various potentials, stemming mainly from the applied stress. If a shear force is applied on a flow unit, the barrier height is reduced in the direction of the force and increased by a similar amount in the opposite direction.

It has been assumed by many researchers (e.g. Mitchell et al. (1968) and Feda (1989)) that rate process theory may also be applied to solids in a state of plastic or viscous flow, when subjected to stress levels in excess of their yield stress. In the case of particulate materials the stresses in question will occur at granular contacts. Rate process theory offers an expression for the sliding velocity $\dot{s}$ of two contacting particles as a function of the ratio $\mu$ between the tangential and normal contact force components, $f^{\mathrm{t}}$ and $f^{\mathrm{n}}$ respectively

$$
\dot{s}=\lambda \frac{2 k T}{h} \exp \left(\frac{-\Delta F}{R T}\right) \sin h\left(\frac{1}{2 k T} \frac{\lambda}{n_{1}} \mu\right)
$$

where

$k=$ Boltzmann's constant, $1.38 \times 10^{-23} \mathrm{~J} / \mathrm{K}$

$h=$ Planck's constant, $6.62 \times 10^{-34} \mathrm{~J} \mathrm{~s}$

$R=$ universal gas constant, $8 \cdot 31 \mathrm{~J} /(\mathrm{mol} \mathrm{K})$

$T=$ absolute temperature, $\mathrm{K}$

$\lambda=$ flow unit, a distance between successive equilibrium positions in the direction of the applied force (see Fig. 2), $\mathrm{m}$ $n_{1}=$ the number of bonds per unit of normal contact force, bonds $/ \mathrm{N}$

$\Delta F=$ activation energy, a measure of the bonding strength, $\mathrm{kJ} / \mathrm{mol}$.

In order to understand the physical meaning of equation (1), this equation can be written for realistically large values of $\lambda \mu / 2 k T n_{1}$ as

$$
\mu=\frac{2 k T n_{1}}{\lambda}\left[\ln \left(\frac{\dot{s} h}{\lambda k T}\right)+\frac{\Delta F}{R T}\right]
$$

or

$$
\mu=B\left[\ln \left(\frac{\dot{s}}{v_{0}}\right)+\frac{\Delta F}{R T}\right]
$$

where

$$
B=\frac{2 k T n_{1}}{\lambda} \text { and } v_{0}=\frac{\lambda k T}{h}
$$

Potential energy

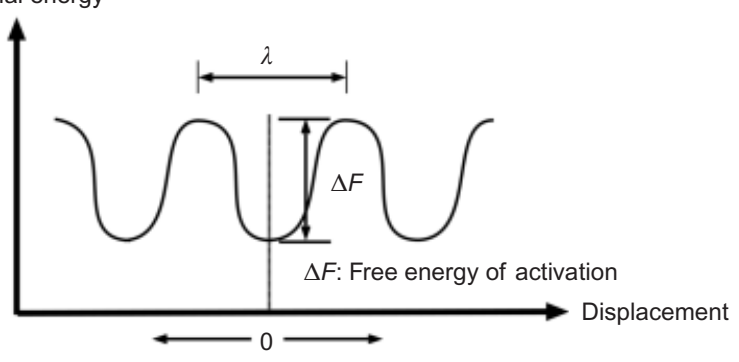

Fig. 2. Energy barriers and activation energy 
Dimensionless parameter $B$ relates the energy of thermal vibration $(k T)$ to the strain energy required to bring two surfaces into intimate contact $\left(\lambda / n_{1}\right)$. Parameter $v_{0}$ has dimensions of velocity arising from a quantum mechanics description of energy and position, which offers a fundamental normalisation of contact creep velocity $\dot{s} . \Delta F / R T$ relates the activation energy $(\Delta F)$ for sliding to the available energy of thermal vibration $(R T)$.

In applying equation (1), Kuhn \& Mitchell (1993) took the following values for the variables: $T=293 \mathrm{~K}\left(20^{\circ} \mathrm{C}\right)$, $\lambda=2.8 \times 10^{-10} \mathrm{~m}, \quad n_{1}=1 \times 10^{9}$ bonds $/ \mathrm{N}, \Delta F=105 \mathrm{~kJ} /$ mol. The significance of each variable is discussed below.

(a) An increase in temperature increases the sliding velocity and the creep rate and should give a decrease in strength and weaken the soil structure.

(b) The flow unit $\lambda$ is taken to be the diameter of an oxygen ion, so that creep involves the displacement of oxygen atoms within the contacting surfaces of a soil's silicate mineral particles (Mitchell \& Soga, 2005). Sliding occurs at a molecular level within the contact zone.

(c) Mitchell et al. (1969) proposed that the number of bonds $n_{1}$ formed between two particles is proportional to the compressive force transmitted at their contact. $n_{1}$ is smaller for stronger materials as the contact area is correspondingly smaller. The strength depends on the number of bonds. The activation energy activates a mole of flow units. The movement of each flow unit may involve rupture of single or several bonds.

(d) Values of activation energy $\Delta F$ have been measured by several investigators and found to lie in the range 84$190 \mathrm{~kJ} / \mathrm{mol}$ (20 to $45 \mathrm{kcal} / \mathrm{mol}$ ) (Mitchell \& Soga, 2005). The values for sand and clay fall in the same range.

Equation (1) can be further reduced to equation (3) with the use of parameters given by Kuhn \& Mitchell (1993) and listed above.

$$
\dot{s}=6.4 \times 10^{-16} \sin h(34 \mu)
$$

According to equation (3), a reduction of the mobilised coefficient of friction $\mu$ at a contact will severely reduce its sliding velocity, which in turn will tend to reduce the creep strain rate of the entire assembly. A plot of equation (3) for Kuhn \& Mitchell's parameter values is shown in Fig. 3. A linear increase in $\mu$ is exhibited for any logarithmic increase in $\dot{s}$ above a lower limit of about $10^{-15} \mathrm{~m} / \mathrm{s}$, corresponding to point $\mathrm{B}$.

This model for creep obviously conflicts with the conventional understanding that 'static friction' exceeds 'dynamic friction'. A modern understanding of friction (Baumberger et

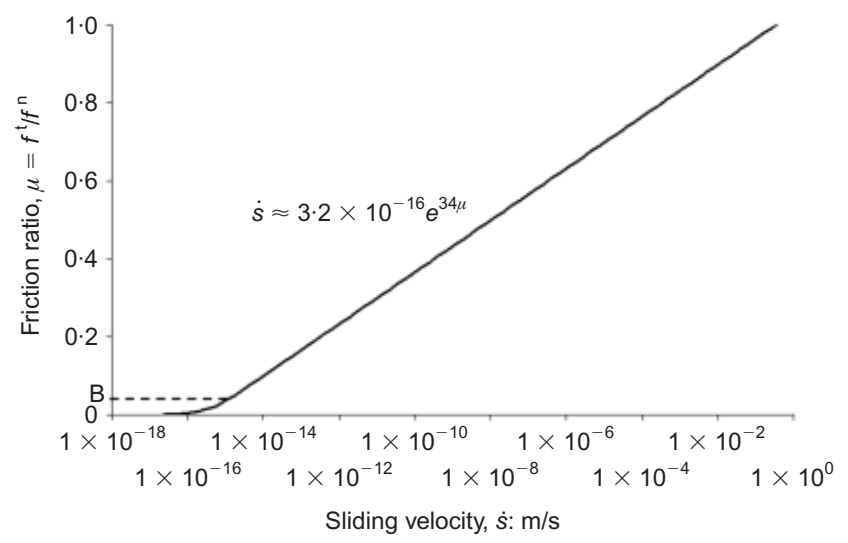

Fig. 3. Plot of the rate process theory equation al., 1999) suggests a micromechanical interpretation based on two phenomena: velocity hardening owing to atomic interactions on a smooth interface, as explored here; and kinetic softening owing to the damaging or melting of initially interlocked asperities on a rough interface. As the shear stress vanishes at $\mu \rightarrow 0$ the Kuhn model of Fig. 3 shows a vanishingly small sliding velocity; this is consistent with a finite but very small rate of thermally activated displacement. In reality, such movements will be locked by asperities. At very large sliding velocities of $1 \mathrm{~m} / \mathrm{s}$ or greater, the Kuhn model provides for large friction coefficients in excess of unity. In reality, such sliding speeds give rise to local melting which would reduce the friction coefficient. An extension of the current work to encompass both thermal activation and particle roughness would be necessary if the complex strainhardening-softening data of Kiyota \& Tatsuoka (2006), for example, were to be fitted. It has been felt appropriate here to focus only on the coupling between the velocity-hardening of grain contacts and the interlocking of frictional but geometrically smooth grains.

Rate process theory on its own can not explain the dependence of soil strain rate on time when temperature and stress conditions are held constant, nor quantify the relationship between macroscopic deviator stress and creep strain rate. These effects only emerge when the behaviour of an assembly of particles is considered. Accordingly, this implementation of rate process theory has been incorporated into three-dimensional (3D) DEM, following the approach of Kuhn \& Mitchell (1993), to simulate the creep behaviour in granular materials. This will lead to a discussion of its relationship with recently published data.

\section{DEM SIMULATIONS}

Soil creep was investigated using a DEM computer simulation called Particle Flow Code in 3 Dimensions $\left(\mathrm{PFC}^{3 \mathrm{D}}\right)$ from Itasca Consulting Group (ICG, 2003). The program models the mechanical behaviour of assemblies of spheres by monitoring their interactions (Cundall \& Strack, 1979). This program uses two basic entities (i.e. balls and walls), and offers a means of modelling entire boundary value problems directly. Contact forces that arise from the interaction of these entities are used to calculate the accelerations of each ball using Newton's second law, and the accelerations are integrated to give velocities and displacements (and hence new contact forces by way of a contact constitutive law), using an explicit time-stepping scheme. The normal and tangential contact stiffnesses were furnished by linear elastic springs. A rate-process contact model was added to $\mathrm{PFC}^{3 \mathrm{D}}$ as a $\mathrm{C}++$ function compiled as a DLL (Dynamic Link Library) file and linked to $\mathrm{PFC}^{3 \mathrm{D}}$; details can be found in Kwok (2008).

The shear force between two objects in contact is generally limited by a simple frictional law with an input coefficient of friction (Coulomb's equation)

$$
F_{\max }^{\mathrm{s}}=\mu\left|F_{i}^{\mathrm{n}}\right|
$$

where $F_{\max }^{\mathrm{s}}$ is the maximum possible shear contact force, $\mu$ is the minimum coefficient of friction of the two objects and $F_{i}^{\mathrm{n}}$ is the normal component of the contact force at the contact point. In what follows, however, $\mu$ is taken to vary with contact sliding speed $\dot{s}$ as given in equation (3).

\section{Simulation steps}

Sample creation. A sample of synthetic material in $\mathrm{PFC}^{3 \mathrm{D}}$ is represented as an assembly of spherical particles as shown in Fig. 4. The sample was generated by random creation of non- 


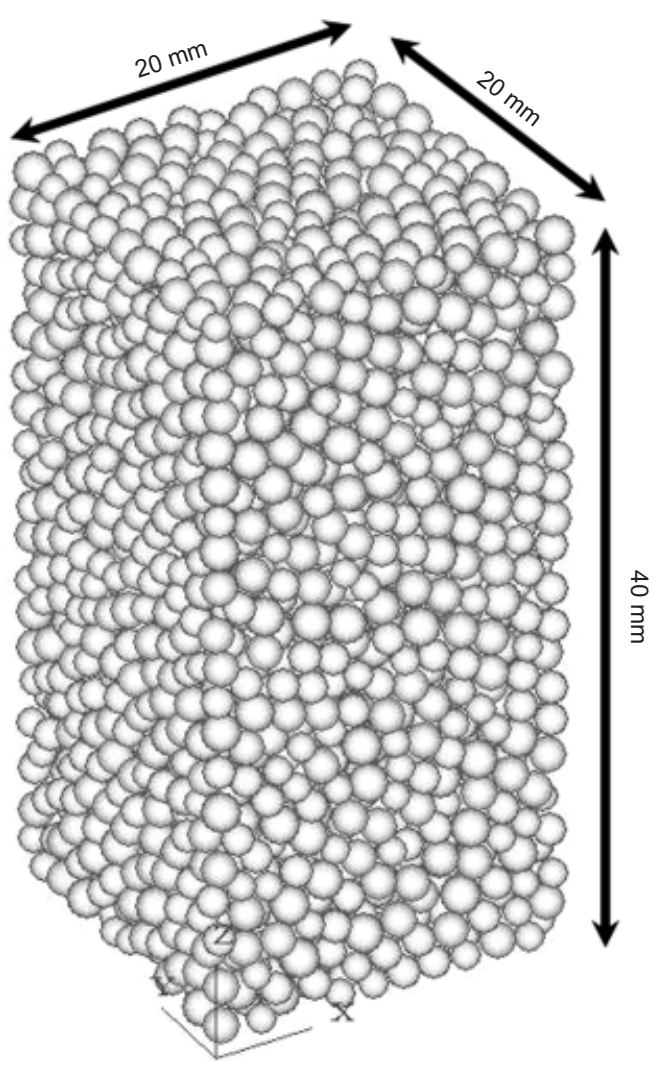

Fig. 4. Initial assembly of spheres

contacting spheres, in which particles with an initially reduced radius are randomly generated inside the confining walls, prior to their subsequent expansion. The sample size, particle diameter and porosity were specified so that the number of particles required was determined to satisfy the specifications. The values of the parameters used in the DEM model are summarised in the Table 1.

Isotropic compression. The assembly was first brought to an isotropic stress of $1 \mathrm{MPa}$. The sample was loaded by moving the six walls inwards. The top and bottom walls simulated loading platens and the lateral walls provided confinement. The stress is estimated from the summation of all contact forces acting on a parallel pair of walls, then dividing by their area. All stress components are counted.

Drained triaxial compression test. The sample was loaded in the vertical direction in a strain-controlled fashion by specifying the velocities of the top and bottom walls $(0.001 \mathrm{~m} / \mathrm{s})$ giving a strain rate of $5 \% / \mathrm{s}$. This relatively rapid

Table 1. Properties of the DEM assembly

\begin{tabular}{l|c}
\hline Quantity & Value \\
\hline Sample size: mm & $40 \times 20 \times 20$ \\
Number of spheres & 3421 \\
Diameter of spheres: $\mathrm{mm}$ & $1 \cdot 5-2 \cdot 0$ \\
Density of solids: $\mathrm{kg} / \mathrm{m}^{3}$ & 2650 \\
Initial voids ratio & 0.67 \\
Initial porosity & $0 \cdot 4$ \\
Normal contact stiffness: N/m & $1 \times 10^{6}$ \\
Tangential contact stiffness: N/m & $1 \times 10^{6}$ \\
\hline
\end{tabular}

compression simulated the usual rapid application of compressive load at the beginning of laboratory creep tests. The horizontal stress was maintained nearly constant by continually adjusting the width and length of the assembly as the vertical compression proceeded.

Drained creep test. After the assembly had been compressed to a given stress level, it was allowed to creep while the stresses in all directions were maintained constant. This was accomplished by continually adjusting the length, width and height of the assembly. These adjustments are required due to the small sliding movements that are occurring between the particles during each time step. The small changes in stresses that have resulted from the most recent width and height adjustments were used to estimate appropriate adjustments for the next time step.

\section{DEM RESULTS}

The results of rapid compression tests with different values of $\mu$ are shown in Fig. 5 where the deviator stress $q$ has been normalised with respect to the initial confining pressure $p_{0}$, together with an auxiliary non-linear scale indicating the mobilised secant angle of internal friction. There are two series of simulations, one series with conventional rate-independent $\mu$ values of $0,0.5$ and 0.9 , and one series with $\mu$ at sliding contacts conforming to equation (3) with each contact sliding speed $\dot{s}$ derived from successive steps of the DEM simulation. In these latter tests, the initial value of $\mu$ prior to contact sliding was taken to be 0 (equivalent to having given an infinite time for creep to occur under $p_{0}$ prior to applying $q$ ), 0.5 or 0.9 . It is shown that with the use of $\mu$ varying with $\dot{s}$, the samples tested at a constant axial strain rate of $5 \% / \mathrm{s}$ reached higher peak strength and behaved with greater stiffness on unloading and reloading, than samples tested with a constant value of $\mu$, even when this was taken to be as high as 0.9 . It seems that low-velocity sliding, permitted at low mobilised friction coefficients by the creep model of equation (1), is helpful in creating a strong microstructure with many nearly-normal interparticle contact forces. This would also explain why the variable- $\mu$ simulation beginning with zero $\mu$ is the stiffest of the three variable- $\mu$ simulations.

A series of creep tests at different stress levels is illustrated in Fig. 6. The deviator stress $q$ in Fig. 6(a) has been normalised with respect to the maximum deviator stress $q_{\max }$. A soil sample was sheared in triaxial compression to various stress-strain states $A$. At each state A, the creep process is initiated by switching to the maintenance of constant stress. As creep occurs, the strain state moves towards points such as B. All tests were performed under drained conditions, which naturally produced both deviator and volumetric deformations. Fig. 6(b) shows the volumetric strain plotted against the axial strain. There is an initial elastic contraction owing to the very small compressions of an unchanging number of contacts when the mean stress first starts increasing. Dilation occurs as the test continues. It is shown that there is a unique dilatancy relation applicable to all the simulations. The effect of creep at constant stress is to promote additional strains which follow this unique relation.

The initial triaxial compression phase of the tests was conducted with variable $\mu$, starting with $\mu=0$, as described earlier. After an initial acceleration phase lasting $0.08 \mathrm{~s}$, the triaxial compression phase of each test was conducted at $5 \% / \mathrm{s}$. Axial strain rates are plotted in Fig. 7 beginning with triaxial compression and continuing with all the creep stages 


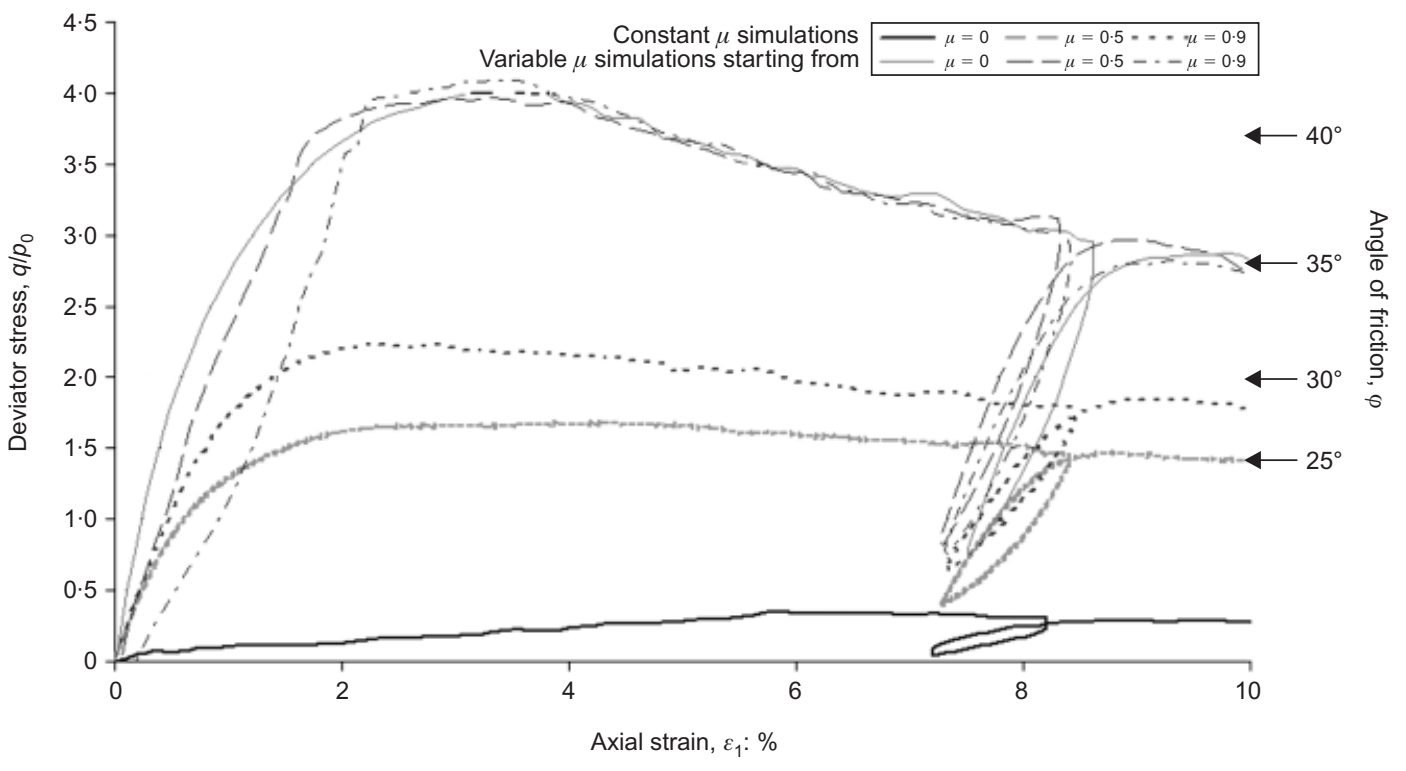

Fig. 5. Stress-strain curves with different fixed and changing coefficients of friction

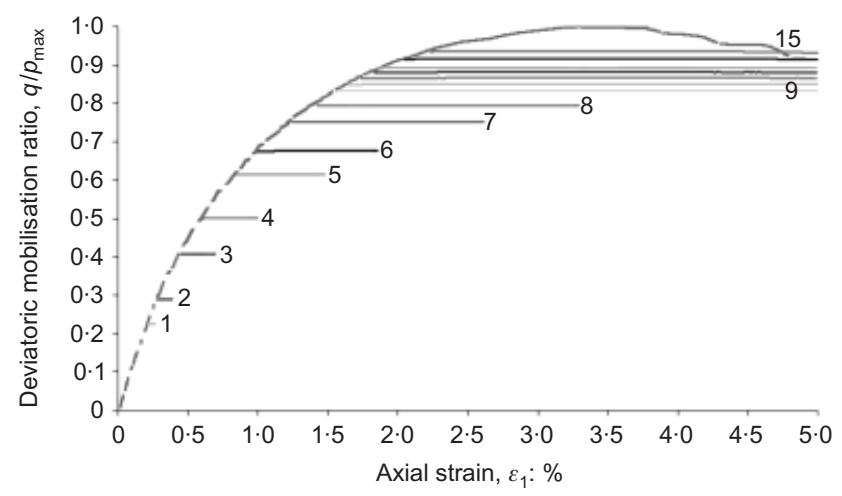

(a)

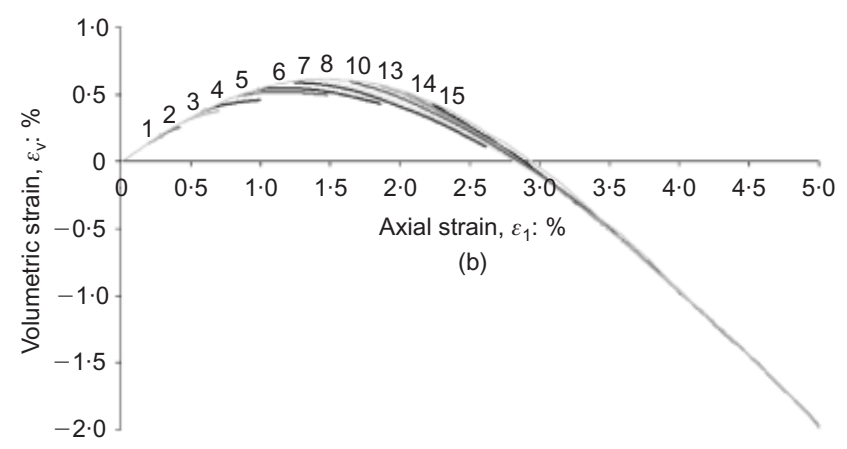

Fig. 6. Triaxial compression tests with creep permitted at various deviator stress levels: (a) normalised deviator stress plotted against axial strain; (b) volumetric strain plotted against axial strain

$\mathrm{AB}$. The reference time was taken at the beginning of the triaxial compression test.

The creep curves show a decrease followed by an increase in strain rate with time, a form of behaviour typical of many other materials. In this figure the higher lines correspond to tests with a greater applied deviator stress. The decelerating creep behaviour of the numerical simulations at lower deviator stresses is similar to that of real soils, with the logarithm of strain rate decreasing in a nearly linear fashion with the logarithm of time. It is found that the gradient $m$ varied between -0.8 and -1 and increased only weakly with the

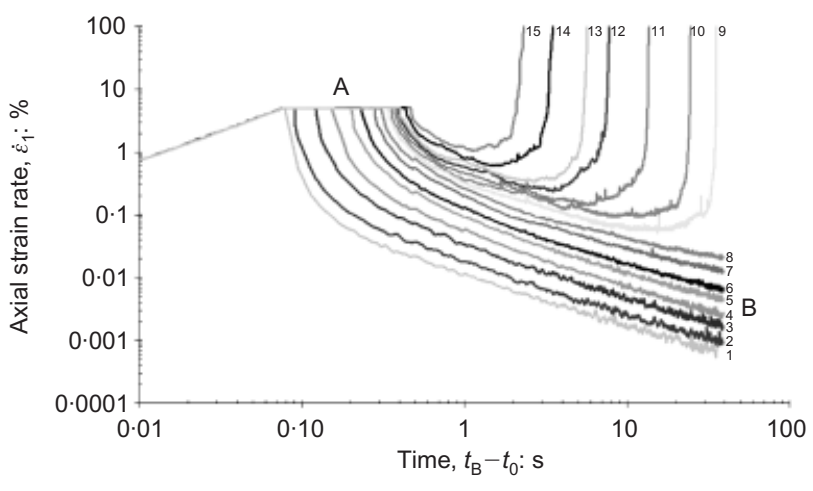

Fig. 7. Strain rate plotted against time on a log-log plot, for simulations of triaxial compression and creep

deviator stress. An increase in proportional deviator stress does shift the lines upwards in Fig. 7, however.

Each creep test was terminated after about $40 \mathrm{~s}$ of simulated creep or after creep failure had begun. Creep-induced failure, with a rapidly increasing strain rate, is ultimately exhibited in these simulations where the sustained deviator stress exceeded about $80 \%$ of its peak value in a simple triaxial test at the same confining pressure. However, this ratio depends on the strain rate chosen for the reference triaxial test, and also on the permitted duration of creep. It will be shown that a better rule for the onset of creep failure can be based on micromechanical considerations linked to strain, not stress.

The strain rate curves of Fig. 7 are integrated to produce $\log$-log plots of axial strain plotted against time in Fig. 8. It is now clear that within the same duration of creep time $(40 \mathrm{~s})$, samples with higher deviator stress crept more and achieved a higher axial strain. Creep-induced failure can now be seen to initiate when the total axial strain reaches about $4 \%$, and to be the predictable outcome of creep at any deviator stress level, albeit very much delayed in the case of low deviator stress ratios. It is interesting to note that Campanella \& Vaid (1974) found creep rupture to occur in clay at about $4 \%$ axial strain.

It appears that strain damages the microstructure of the sample. The nature of this damage is clear from Fig. 6(b). The microstructure has a maximum dilatancy rate $\mathrm{d} \varepsilon_{\mathrm{v}} / \mathrm{d} \varepsilon_{1} \approx$ -1 which is achieved at a unique axial strain $\varepsilon_{1} \approx 4 \%$. This 


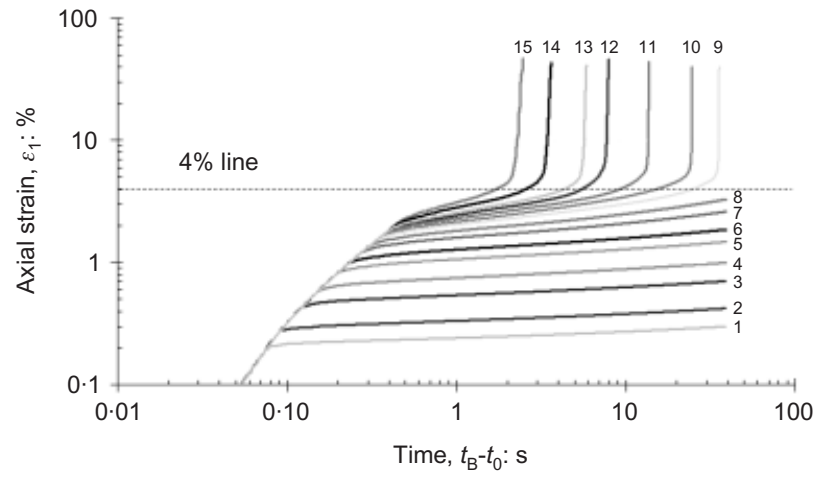

Fig. 8. $\log ($ axial strain) against $\log ($ time) during triaxial compression and creep simulation of a 3421 particle assembly

is also the approximate strain at which the monotonic triaxial compression test reached its peak strength, as required by stress-dilatancy theory (Rowe, 1969). A maximum dilatancy rate of -1 also conforms to the data of strength and dilatancy of sands reported by Bolton (1986). Evidently, the phenomenon of 'creep rupture' is nothing more complicated than the acquisition (by initial loading followed by creep) of a state of strain associated with peak dilatancy. In the simulations reported here, the wall prevents localisation in shear bands which would otherwise be expected during post-peak dilatant strain-softening.

\section{COMPARISONS WITH LABORATORY DATA}

The creep behaviour of Ham River Sand set up under anisotropic stress $(K=0.45)$ and with a voids ratio of 0.66 , as observed by Kuwano \& Jardine (2002), is plotted in Fig. 9. It is seen superficially to resemble the steady creep rate reduction exhibited for small deviatoric stress ratios on the similar plot in Fig. 7 of the logarithm of the strain rate decreasing in a nearly linear fashion with the logarithm of time, the slopes in the two figures being similar (approximately -0.8). However, the absolute strain rates from the DEM were much higher, by a factor of more than 10 . The reasons for this overestimation of strain rate magnitudes might be related to deficiencies in the DEM of creep represented by equation (1), or to the use of inappropriate values of parameters (such as activation energy $\Delta F$ ) in equation (1), or to differences between the detailed stress history in the laboratory tests and the DEM simulations, or simply to assumptions made in translating from $K=0.45$ in Fig. 9 to $q / q_{\max } \approx 0 \cdot 3$ in Fig. 7. Further comparisons are required.

Figure 10 compares both the power-law creep gradient $m$ and the magnitude of strain rate after $t=10$ minutes from the triaxial test data of real soils with values obtained from DEM simulations. The two-dimensional (2D) simulations of discs carried out by Kuhn (1987) and the PFC ${ }^{3 \mathrm{D}}$ simulations of the present study are compared in Figs 10(a) and 10(b) against sands, and in Fig. 10(c) and 10(d) against clays. By comparing the data in Fig. 10(b) and 10(d), it seems that sands creep slightly less than clays at the same degree of mobilisation of deviator stress, but the amount of creep in sand has been observed to increase at high confining stresses when grain crushing becomes important (Yamamuro \& Lade, 1993).

For smaller deviatoric mobilisations, $q / q_{\max }<0 \cdot 5$, the $m$ parameter of real sands (in Fig. 10(a)) appears to be in the range of -0.9 to -1.0 , as is the $m$ parameter from $\mathrm{PFC}^{3 \mathrm{D}}$ reported here. The 2D DEM simulations of Kuhn \& Mitchell (1993) gave $m \sim-0 \cdot 7$. In the same range of smaller deviatoric mobilisation, the magnitude of the $m$ parameter of real clays (Fig. 10(c)) is a little lower than real sands at about -0.8 . However, it is noticeable that real clays show a reducing gradient $m$ at higher deviatoric mobilisations $q / q_{\max }>0 \cdot 5$, reminiscent of the onset of creep-induced failure in the DEM simulations, but rather earlier. This DEM model may not be a good representation of clays because of the limitation of the spherical shape of its indestructible

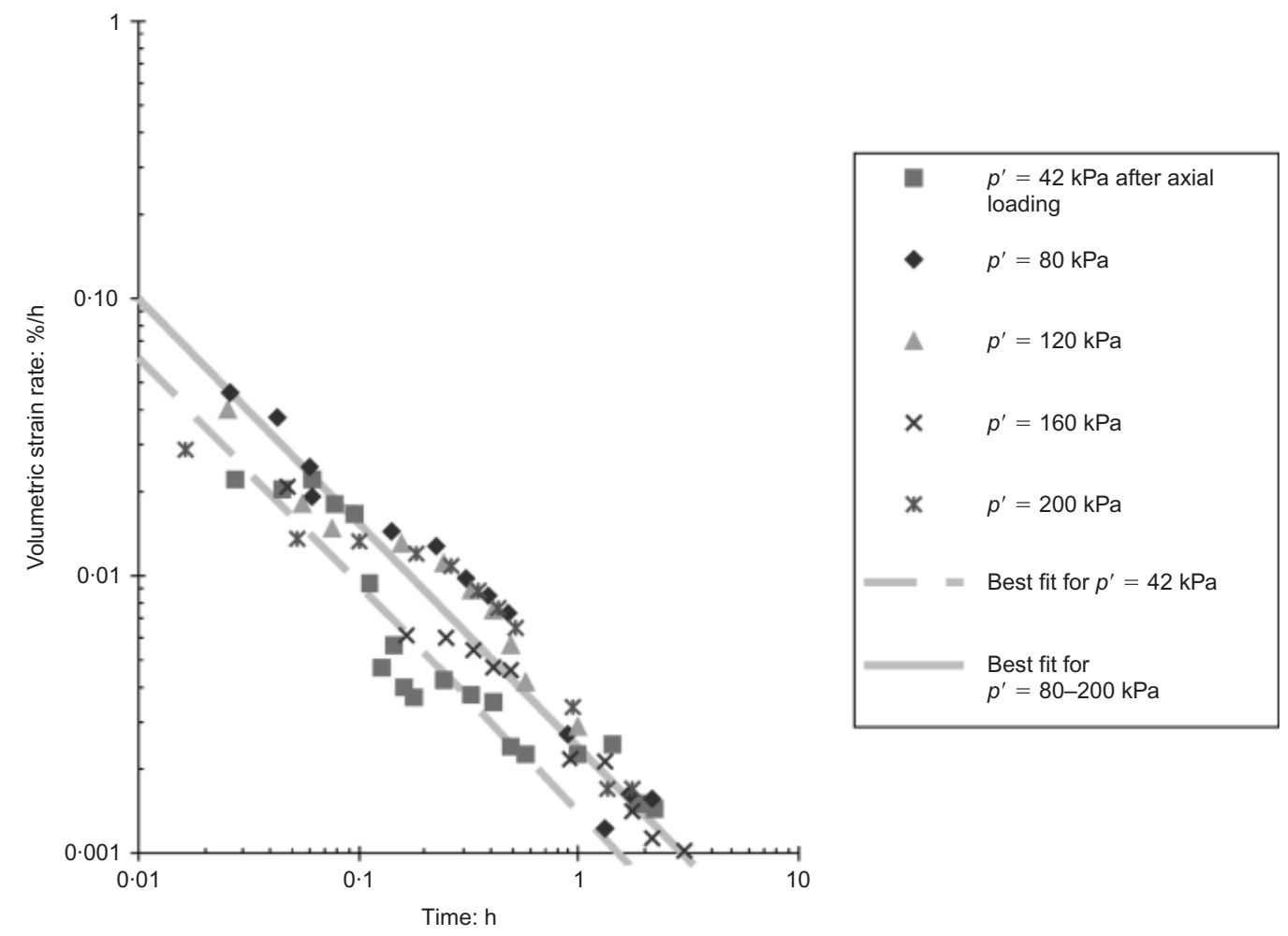

Fig. 9. Decay of creep strain rate of Ham River Sand set up under anisotropic stress $(K=0 \cdot 45)$ and with a voids ratio of 0.66 (from Kuwano \& Jardine, 2002) 


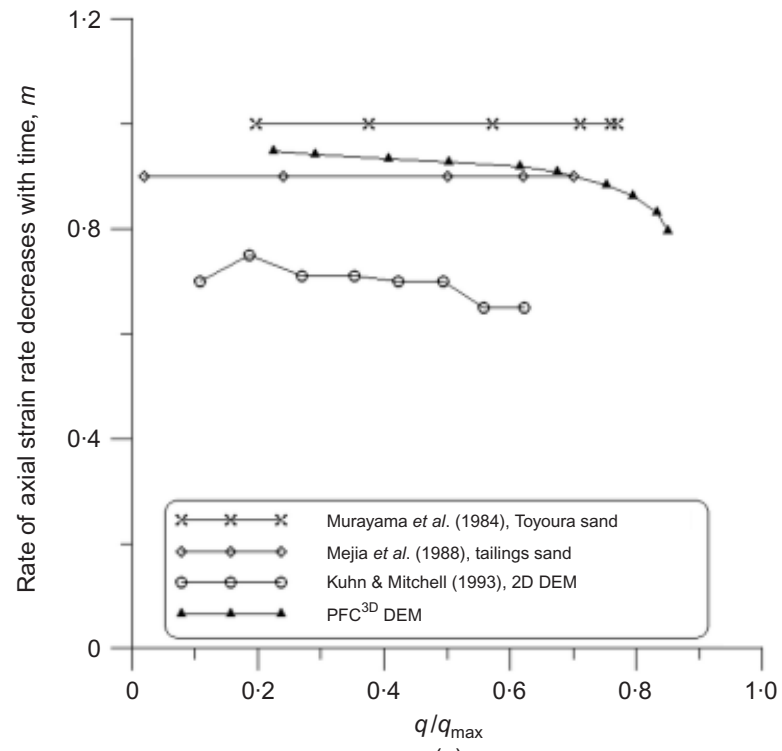

(a)

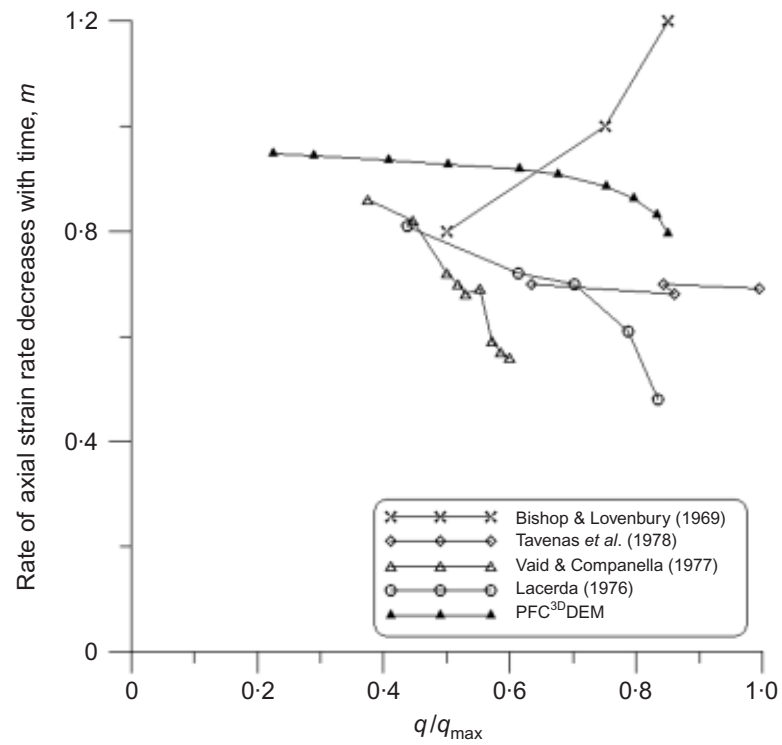

(c)

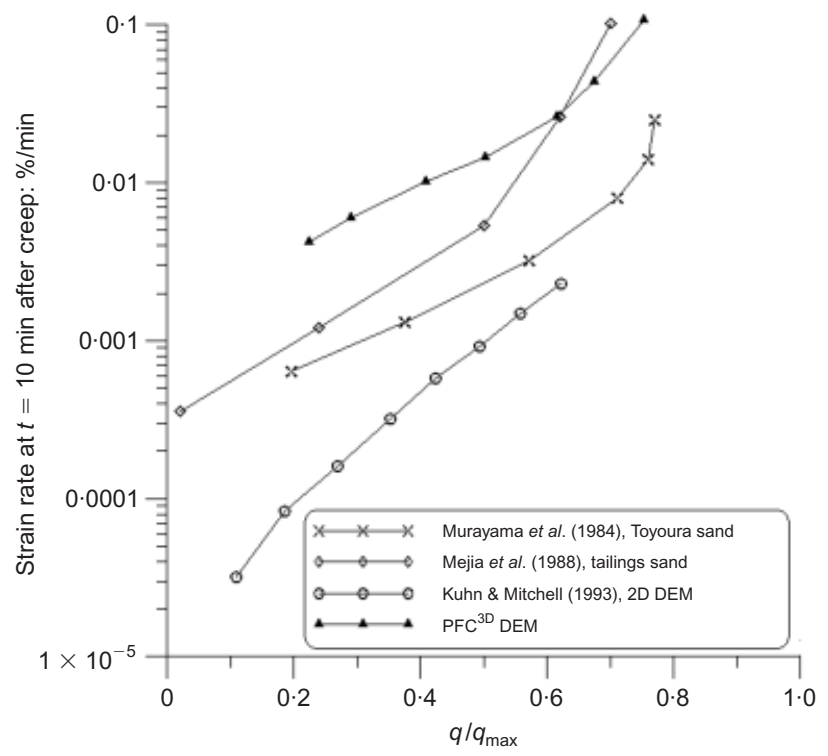

(b)

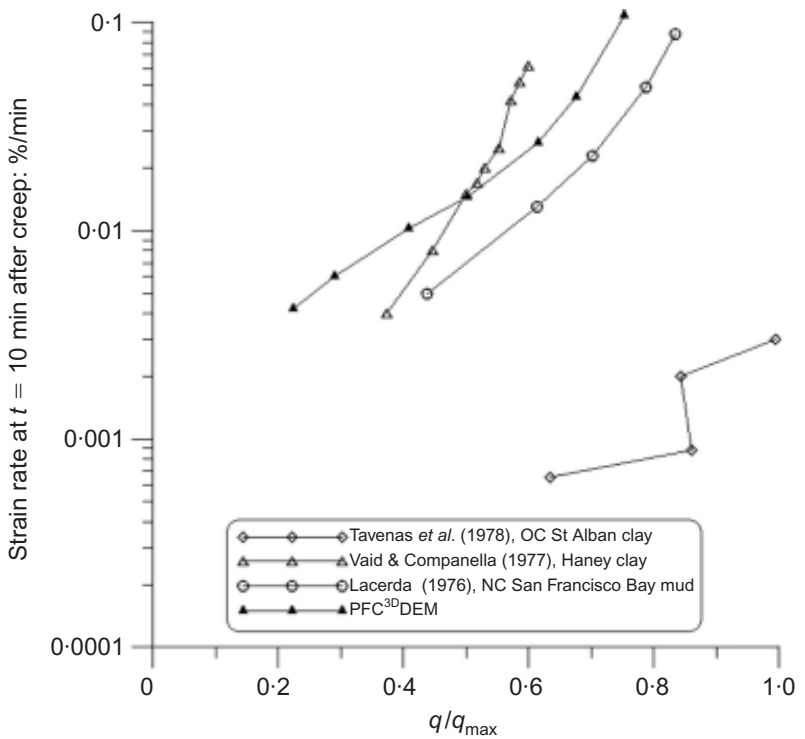

(d)

Fig. 10. (a) Comparisons of rate of reduction of $\log ($ strain rate) with $\log ($ time) at different deviator stress levels for sands; (b) comparisons of strain rate after $t=\mathbf{1 0} \mathbf{m i n}$ of creep at different deviator stress levels for sands; (c) comparisons of rate of reduction of $\log ($ strain rate) with $\log ($ time) at different deviator stress levels for clays; (d) comparisons of strain rate after $t=10$ min of creep at different deviator stress levels for clays

grains. Perhaps crushing of agglomerates, in addition to interparticle sliding, would need to be simulated in order to better simulate creep in clays.

In terms of the magnitude of creep strains, it is the strain rate $10 \mathrm{~min}$ after the start of creep, given in Figs 10(b) and 10(d), which gives the best indication. The PFC ${ }^{3 \mathrm{D}}$ simulations of creep, compared with the data of sands, seem to produce the correct functional relationship with the degree of deviator mobilisation, but with strain rates about 5 times too large. Interestingly, Kuhn \& Mitchell's 2D DEM simulations produced a strain rate about 5 times too low, even though they used the same rate process approach with the same parameters. Apparently, the availability of degrees of freedom in three dimensions is highly significant.

The 3D simulations are rather closer to the creep data of clays in Fig. 10(d), except for the very small creep observed in overconsolidated St Alban clay by Tavenas et al. (1978). It might be conjectured that overconsolidation not only stabilises the soil structure, but also introduces a negative strain-rate history effect. With regard to the two normally consolidated clays, the DEM simulations produce values of strain rate at $10 \mathrm{~min}$ which are about 2 times too high. Recalibration of DEM creep can be achieved by altering the activation energy $\Delta F$ for contact sliding.

\section{DISCUSSION}

Rate process theory is tantamount to specifying that the coefficient of friction $\mu$ is a linear function of the logarithm of sliding velocity $\dot{s}$, according to equations (1) or (2). The fundamental physical constants $R, k$ and $h$ take known, fixed values. Intrinsic material parameters $\lambda$ and $n_{1}$ take values dependent on atomic properties which are regarded as relatively well known. Mitchell et al. (1968) and Kuhn \& Mitchell (1993) therefore took the view that the experimental determination of creep rate at a known absolute temperature was tantamount to a determination of activation energy $\Delta F$. This computer modelling study will take the same 
approach, by calculating the activation energy required for the simulations to match the data of published experiments.

The creep strain rate obtained from the DEM of densely packed spheres is approximately 5 times larger than the data of real sands in Fig. 10(b). In order to achieve a lower strain rate in the DEM simulation, a higher activation energy has to be used. In Fig. 11, it is shown that the logarithm of strain rate decreases linearly with the activation energy. For the strain rate after $10 \mathrm{~min}$ of creep under $K=0.45(q /$ $\left.q_{\max }=0.29\right)$, to be reduced by factor 5 to $0.6 \times 10^{-3} \% / \mathrm{min}$, the activation energy has to increase from $105 \mathrm{~kJ} / \mathrm{mol}$ to $140 \mathrm{~kJ} / \mathrm{mol}$. A higher activation energy of $140 \mathrm{~kJ} / \mathrm{mol}$ was accordingly used to re-simulate the creep test under an anisotropic state of stress ratio $K=0.45$ ( or $q / q_{\max }=0.29$ ), and the result is indicated as $2 \mathrm{~B}$ in Fig. 12. The original curve with activation energy of $105 \mathrm{~kJ} / \mathrm{mol}$ is indicated as $2 \mathrm{~A}$. It is interesting to note that the slope $m$ of primary creep rate reduction remains unchanged in Fig. 12 while the ultimate creep strains are reduced to the required level.

Although a dense packing of spherical grains may seem inherently inadequate to the task of representing the microstructure of clays, it is interesting to note that Fig. 10 demonstrated a similar pattern of behaviour for the experimentally observed creep of clays and sands, and a similar pattern to the DEM simulations, at least up to a mobilisation factor $\left(q / q_{\max }\right)=0 \cdot 5$. In this range it has been shown that the use of a lower activation energy, $115 \mathrm{~kJ} / \mathrm{mol}$ for clay compared with $140 \mathrm{~kJ} / \mathrm{mol}$ for sand, permits the DEM simulations roughly to satisfy available data of clay creep. However, geotechnical engineers generally encounter creep only in the 'secondary consolidation' phase of oedometer tests on clays, after almost all excess pore pressures have dissipated. If $m=1$ is taken as representative of the typical gradient of $\log \dot{\varepsilon}$ against $\log t$, it is possible to write (using logarithm to a natural base, $\ln$ )

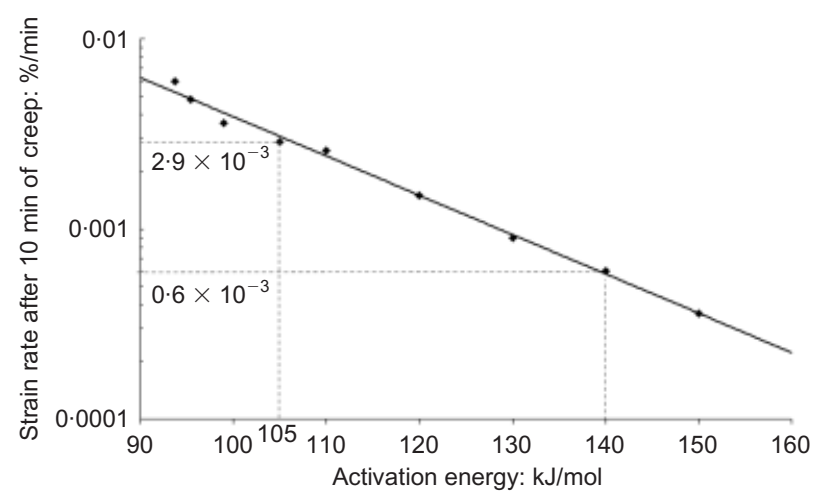

Fig. 11. Strain rate after $10 \mathrm{~min}$ of creep and under anisotropic states $(K=0 \cdot 45)$ against activation energy.

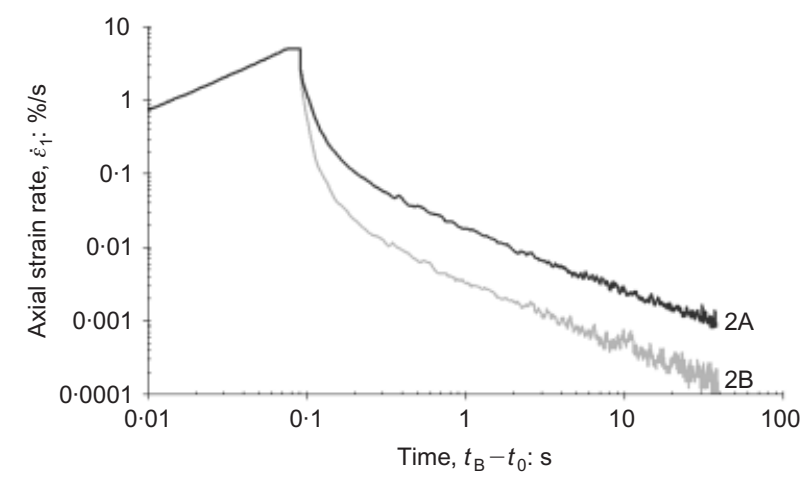

Fig. 12. $\log ($ strain rate) against $\log ($ time) during triaxial compression and creep simulation with higher activation energy

$$
\begin{aligned}
\ln \dot{\varepsilon} & =\ln \dot{\varepsilon}_{0}-\ln \left(t / t_{0}\right) \\
& =\ln \left(\dot{\varepsilon}_{0} t_{0} / \mathrm{t}\right)
\end{aligned}
$$

so

$$
\dot{\varepsilon}=\frac{\dot{\varepsilon}_{0} t_{0}}{t}
$$

and

$$
\varepsilon=\dot{\varepsilon}_{0} t_{0} \ln \left(t / t_{0}\right)
$$

The coefficient of secondary compression $C_{\alpha}$ used by engineers to describe the slope of a graph of $\varepsilon$ against $\log _{10}$ $t$ is therefore equal to $2 \cdot 3 \dot{\varepsilon}_{0} t_{0}$ where $\dot{\varepsilon}_{0}$ is the initial creep rate at time $t_{0}$ in soil with a power-law creep gradient $m=-1$. Such differences in the formalism of empirical models used for different soils may mask similar creep micro-mechanisms. Further DEM work on creep exploring aspects such as grain shape, microstructural arrangement and grain roughness effects would be valuable.

\section{CONCLUSIONS}

(a) Kuhn \& Mitchell (1993) invoked a rate process theory of frictional sliding as the origin of creep in granular materials, using 2D simulations. Their creep strain rates were about 5 times lower than those observed in real tests on sand, but they did replicate the characteristic reduction of $\log$ creep rate with $\log$ time seen in experimental data and described as 'primary' or 'powerlaw' creep. Using precisely the same parameters as Kuhn \& Mitchell, but in 3D simulations, creep strain rates have been obtained that are about five times higher than the data of real sands. Evidently, the creep within a 3D structure of grains will be orders of magnitude greater than that within a $2 \mathrm{D}$ structure of discs.

(b) In order to match more closely with laboratory data, the activation energy of atomic sliding in $\mathrm{PFC}^{3 \mathrm{D}}$ simulations of sands needs to be increased from Kuhn \& Mitchell's $105 \mathrm{~kJ} / \mathrm{mol}$ to about $140 \mathrm{~kJ} / \mathrm{mol}$. Normally consolidated clays creep more than sands, and an activation energy of about $115 \mathrm{~kJ} / \mathrm{mol}$ is required in these $3 \mathrm{D}$ simulations to match experimental creep strain rates.

(c) A key characteristic of soil creep, the power law reduction of creep rate with time observed at low degrees of shear strength mobilisation $\left(q / q_{\max }<0.5\right)$ in tests such as oedometer tests, is an emergent phenomenon of all these DEM simulations. The slopes $m$ of these log-log plots for sands and clays fall in the range of -0.8 to $-1 \cdot 0$, just as does the slope offered by all the DEM simulations, irrespective of the parameters used in the rate process expression. Creep deceleration under low stress ratios is apparently inevitable in granular materials, as the strong force network rids itself of weaker contacts.

(d) It is shown that creep owing to contact sliding can induce both shear and dilation, depending on the magnitude of total strain. Creep-induced plastic failure occurred predictably after about $4 \%$ of axial strain for the dense packing studied here, which is roughly the point of peak strength in a triaxial test simulation and the point of maximum dilatancy rate. Ultimately, therefore, creep failure appears to be inevitable in these simulations if deviator stresses are maintained, albeit long-delayed if the deviator stress is small compared with the peak strength.

(e) These simulations have therefore suggested micro- 
mechanisms appropriate to both the 'primary' (hardening, power law) and 'tertiary' (dilatant, softening) phases of creep defined in Fig. 1. 'Secondary' creep is seen here simply as a temporary point of balance between these two mechanisms.

$(f)$ In summary, therefore, DEM featuring rate process frictional sliding provides persuasive simulations of diverse creep phenomena in soils. Practically, this is achieved by introducing only one extra parameter, a linear rate of increase of the coefficient of contact sliding with the logarithm of the sliding speed. From a theoretical perspective, the reasonable assumption of a lower activation energy for clays than for sands is the first step necessary to match corresponding laboratory tests. However, the focus here on the thermally activated creep of perfectly smooth grains, avoiding the known additional influence on intergranular friction of potential damage at interlocking contact asperities, should induce caution in extrapolating the significance of these simulations beyond the range of demonstrated accordance with published experimental results. It is possible, for example, that more realistic micromechanical modelling of rough grain contacts would reduce their propensity to creep, and allow the DEM values of activation energy to reduce back to previously published values based on experiments. Further work on the DEM of soil creep would be advantageous.

\section{NOTATION}

$C_{\alpha}$ coefficient of secondary compression

$\Delta F$ activation energy, a measure of the bonding strength

$F_{i}^{\mathrm{n}} \quad$ normal component of contact force

$F_{\text {max }}^{\mathrm{s}}$ maximum allowable shear contact force

$f^{t}$ tangential contact force components

$f^{\mathrm{n}}$ normal contact force components

$h$ Planck's constant, $6.62 \times 10^{-34} \mathrm{~J} \mathrm{~s}$

$k$ Boltzmann's constant, $1.38 \times 10^{-23} \mathrm{~J} / \mathrm{K}$

$m$ slope of plot of logarithm of axial strain rate against logarithm of time

$n_{1}$ number of bonds per unit of normal contact force

$p_{0} \quad$ initial mean stress

$q$ deviator stress, $\sigma_{1}-\sigma_{3}$

$q_{\max }$ maximum deviator stress

$R$ universal gas constant, $8 \cdot 31 \mathrm{~J} /(\mathrm{mol} \mathrm{K})$

$\dot{S}$ sliding velocity

$T$ absolute temperature

$\Delta t$ time step

$t$ time

$t_{0} \quad$ initial time

$v_{0} \quad$ a characteristic sliding velocity

$\beta$ deviator stress intensity

$\varphi$ coefficient of friction

$\varepsilon_{1} \quad$ axial strain

$\varepsilon_{\mathrm{v}}$ volumetric strain

$\dot{\varepsilon}_{0} \quad$ initial axial strain rate

$\dot{\varepsilon}_{1} \quad$ axial strain rate

$\lambda$ flow unit, a distance between successive equilibrium positions in the direction of the applied force

$\mu$ coefficient of friction

\section{REFERENCES}

Augustesen, A., Liingard, M. \& Lade, P. V. (2004). Evaluation of time-dependent behaviour of soils. ASCE Int. J. Geomech. 4, No. 3, 137-156.

Baumberger, T., Berthoud, P. \& Caroli, C. (1999). Physical analysis of the state- and rate-dependent friction law: II Dynamic friction. Phys. Rev. B 60, 3928-3939.

Bishop, A. W. \& Lovenbury, H. T. (1969). Creep characteristics of two undisturbed clays. Proc. 7th ICSMFE, Mexico 1, 29-37.

Bolton, M. D. (1986). Strength and dilatancy of sands. Géotechnique 36, No. 1, 65-78, doi: 10.1680/geot.1986.36.1.65.

Bowman, E. T. \& Soga, K. (2003). Creep, ageing and microstructural change in dense granular materials. Soils Found. 43, No. 4, 107-117.

Burland, J. B. \& Burbridge, M. C. (1985). Settlement of foundations on sand and gravel. Proc. Instn Civ. Engrs. Part 1 Des. Constr. 78, December, $1325-1381$.

Campanella, R. G. \& Vaid, Y. P. (1974). Triaxial and plane strain creep rupture of an undisturbed clay. Can Geotech. J. 11, No. 1, $1-10$.

Cundall, P. A. \& Strack, O. D. L. (1979). A discrete numerical model for granular assemblies. Géotechnique 29, No. 1, 47-65, doi: $10.1680 /$ geot.1979.29.1.47.

Di Benedetto, H., Tatsuoka, F. \& Masanori, I. (2002). Timedependent shear deformation characteristics of sand and their constitutive modelling. Soils Found. 42, No. 2, 1-22.

Eyring, H. (1936). Viscosity, plasticity and diffusion as examples of absolute reaction rates. J. Chem. Phys. 4, April, 283-291.

Feda, J. (1989). Interpretation of creep of soils by rate process theory. Géotechnique 39, No. 4, 667-677, doi: 10.1680/geot. 1989.39.4.667.

Hyde, A. F. L. \& Brown, S. F. (1976). The plastic deformation of a silty clay under creep and repeated loading. Géotechnique 26, No. 1, 173-184, doi: 10.1680/geot.1976.26.1.173.

Itasca Consulting Group, Inc. (2003). PFC ${ }^{3 \mathrm{D}}$ particle flow code in three-dimensions, version 3.0. Minneapolis: ICG.

Kiyota, T. \& Tatsuoka, F. (2006). Viscous property of loose sand in triaxial compression, extension and cyclic loading. Soils Found. 46, No. 5, 665-684.

Kuhn, M. R. (1987). Micromechanical aspects of soil creep. PhD thesis, University of California, Berkeley.

Kuhn, M. R. \& Mitchell, J. K. (1993). New perspectives on soil creep. ASCE J. Geotech. Engng 119, No. 3, 507-524.

Kuwano, R. \& Jardine, R. J. (2002). On measuring creep behaviour in granular materials through triaxial testing. Can. Geotech. J. 39, $1061-1074$.

Kwok, C. Y. (2008). Micromechanical modelling of soil creep. $\mathrm{PhD}$ thesis, Cambridge University.

Lacerda, W. A. (1976). Stress-relaxation and creep effects on soil deformation. $\mathrm{PhD}$ thesis, University of California, Berkely.

Lacerda, W. A. \& Houston, W. N. (1973). Stress relaxation in soils. Proc. 8th ICSMFE 1/34, 221-227.

Mejia, C. A., Vaid, Y. P. \& Negussy, D. (1988). Time dependent behaviour of sand. Proceedings of the international conference on rheology and soil mechanics (ed. M. J. Keedwell), pp. 312326. London: Elsevier.

Mitchell, J. K., Campanella, R. G. \& Singh, A. (1968). Soil creep as a rate process. ASCE Soil Mech. Found. Div. J. 94, No. SM1, $231-253$

Mitchell, J. K., Singh, A. \& Campanella, R. G. (1969). Bonding, effective stress and strength of soils. ASCE Soil Mech. Found. Div. J. 95, No. SM5, 1219-1246

Mitchell, J. K. \& Soga, K. (2005). Fundamentals of soil behaviour, 3rd edn. New York: John Wiley.

Murayama, S., Michihiro, K. \& Sakagami, T. (1984). Creep characteristics of sands. Soils Found. 24, No. 2, 1-15.

Rowe, P. W. (1969). The relation between the shear strength of sands in triaxial compression, plane strain and direct shear. Géotechnique 19, No. 1, 75-86, doi: 10.1680/geot.1969.19.1.75.

Tavenas, F., Leroueil, S., La Rochelle, P. \& Roy, M. (1978). Creep behaviour of an undisturbed lightly overconsolidated clay. Can. Geotech. J. 15, No. 3, 402-423.

Vaid, Y. P. \& Campanella, R. G. (1977). Time-dependent behaviour of undisturbed clay. ASCE J. Geotech. Engng 103, No. 7, 693709 .

Yamamuro, J. A. \& Lade, P. V. (1993). Effects of strain rate on instability of granular soils. ASTM Geotech. Testing J. 16, No. 3, 304-313. 